Marks, Williamson and Quaine, Rissel, and Haas describe specific uses of data from the Program for monitoring the prevalence and management of asthma and diabetes, local planning and program evaluation, and economic analysis. Quaine et al. examine the use made of data from area health service-specific questions included in the Program, and relationships between the process of survey question development, the extent of analysis, and use of the results.

Three papers focus on survey processes. Baker describes the methods-unique to the Program-used to translate the survey questionnaires into non-English languages. Gorringe and Latham provide a "hands on" perspective on managing telephone survey fieldwork, and maximising its quality. Eyeson-Annan describes mooted changes to the Program, which will evolve to a continuous all-ages data collection from January 2002.

Finally, Atyeo and Rawson provide a national context. They describe the series of health surveys conducted by the Australian Bureau of Statistics, and changes to the composition and frequency of their survey program arising from a recent review.

The articles in this edition of NSW Public Health Bulletin emphasise the quality of the work done by the NSW Health Survey Program, and its key role in informing population health activity in NSW. The Program will face several challenges as it evolves, including increasing use of mobile phones (in 2000, 58.5 per cent of Australian households had at least one mobile phone $)^{10}$ and answering machines, portability of phone numbers, and possibly reduced public cooperation related to increasing telemarketing activity. Building an even better information base for population health in NSW will require the development of new health survey methodologies, and strategies to nurture public support.

\section{REFERENCES}

1. Chey T, Smith WT, Jalaludin B, Salkeld G, Hanratty SJ, Capon AG. Surveillance of health status using telephone methodology: a feasibility study. Sydney: Western Sydney Area Health Service, 1992.

2. Roberts C, Chey T, Capon AG. Surveillance of health status: results of a telephone survey in the Wentworth Health Area. Penrith: Western Sydney Area Health Service, 1992.

3. Williamson M, Jorm L, Cardona M, Chey T. Blacktown Health Survey 1993. Sydney: Western Sydney Area Health Service, 1994.

4. Astbury L, Jorm L. Auburn and Holroyd Health Surveys 1995. Sydney: Western Sydney Area Health Service, 1997.

5. Kolbe A, Gilchrist K, Stubbs N, Clark E. Behavioural Risk Factor Study-Culcairn, Henty, Holbrook. Albury: South West Region Department of Health, 1992.

6. Gilchrist K, Kolbe A. Behavioural Risk Factor SurveyGriffith 1993. Albury: South West Centre for Public Health, 1993.

7. Gilchrist K, Kolbe A. Behavioural Risk Factor SurveyBalranald 1993. Albury: South West Centre for Public Health, 1993.

8. Graham-Clarke P, Howell S, Bauman A, Nathan S. NSW Health Promotion Survey 1994-technical report. Sydney: National Centre for Health Promotion and NSW Department of Health, 1995.

9. Williamson M, Baker D, Jorm L. The NSW Health Survey Program: overview and methods, 1996-2000. Sydney, NSW Department of Health 2001.

10. Australian Bureau of Statistics. Population Survey Monitor. Unpublished tables, 2000.

\title{
USES OF NSW HEALTH SURVEY PROGRAM DATA-A SURVEY OF USERS
}

\section{Clare Banks and Margo Eyeson-Annan \\ NSW Health Survey Program \\ NSW Department of Health}

The Epidemiology and Surveillance Branch of the NSW Department of Health established the NSW Health Survey Program (HSP) in 1996 to consider the need for state and local area-level information about the health of the NSW population. ${ }^{1}$ The Program, as a key element in population health surveillance, has the following objectives. To:

- provide ongoing information on self-reported health status, health risk factors, health service use, and satisfaction with health services, to inform and support planning, implementation and evaluation of health services and programs in NSW;

- collect information that is not available from other sources;
- respond quickly to emerging data needs;

- ensure that the information collected is high quality, timely, and cost-effective.

The HSP comprises a series of population health surveys that provide area health service-level data on health status, risk factors, use of health services, and satisfaction with health services. ${ }^{1}$ The first survey began in September 1997 and focused on the adult population. The survey was repeated in 1998 with minor changes, including the addition of questions on oral health and cervical screening. In 1999, the HSP undertook a survey of the health of older people, and a survey of the health of children is currently in progress.

In early 2001, we conducted a survey of stakeholders and users of the HSP to investigate whether it was meeting its objectives. In particular we examined: 
- how users were accessing the health survey data;

- what actions had been taken as a result of the data;

- who had used the data to make decisions and take actions;

- how the program could better meet the needs of the users.

This article reports the methods and findings of this survey of stakeholders and users.

\section{METHODS}

\section{Sample}

The purpose of the survey was to collect information about as many users and uses of the NSW HSP as possible. Accordingly, a non-probability 'snowball' sampling method was used, with three main target groups:

- key staff within the NSW Department of Health who were known to have used data from the HSP;

- potential and actual users of the HSP, compiled from lists of members of relevant committees and other groups, including: NSW Health Survey Program Steering Committee; NSW Health Survey Technical Working Group; NSW Health Survey Methodology Working Group; NSW Child Health Survey Technical Expert Group; NSW Older Peoples Survey Technical Advisory Group; Chief Executive Officers of NSW Area Health Services; National Computer Assisted Telephone Interviewing Technical Reference Group (CATI-TRG); NSW Epidemiology Special Interest Group (Epi-SIG); and NSW Health Promotion Research and Evaluation Coordinators;

- other possible users of the HSP suggested by users from the previous two groups.

\section{Survey Instrument}

Key informants from the NSW Department of Health were surveyed using unstructured face-to-face interviews.

Other potential users of the HSP were surveyed using a brief questionnaire consisting of seven questions. The questions addressed method of access to the survey data (unit record and/or summary information), types of uses of survey data, and topic areas of the data used. The survey also included questions seeking information on other known users of the survey data, and suggested improvements to the HSP.

\section{Data Collection}

The questionnaire was sent to potential users of the HSP by email. Hard copies were distributed at a meeting of the NSW Epidemiology Special Interest Group.

Completed surveys were returned by email, fax, or post. Completed surveys were entered into a database for analysis.

\section{RESULTS}

\section{Respondents}

Of the 230 questionnaires distributed (217 initially and 13 as a result of information from other recipients), 35 were returned by respondents who had used HSP data.

The respondents included health service managers, epidemiologists, project officers, consultants, research officers and health promotion officers. The data had been used within the NSW Department of Health, and by area health services, research institutions and universities, other government departments, specialist health services and private consultants.

\section{FIGURE 1}

TYPES OF USES OF NSW HEALTH SURVEY PROGRAM INFORMATION [ $N=116]$

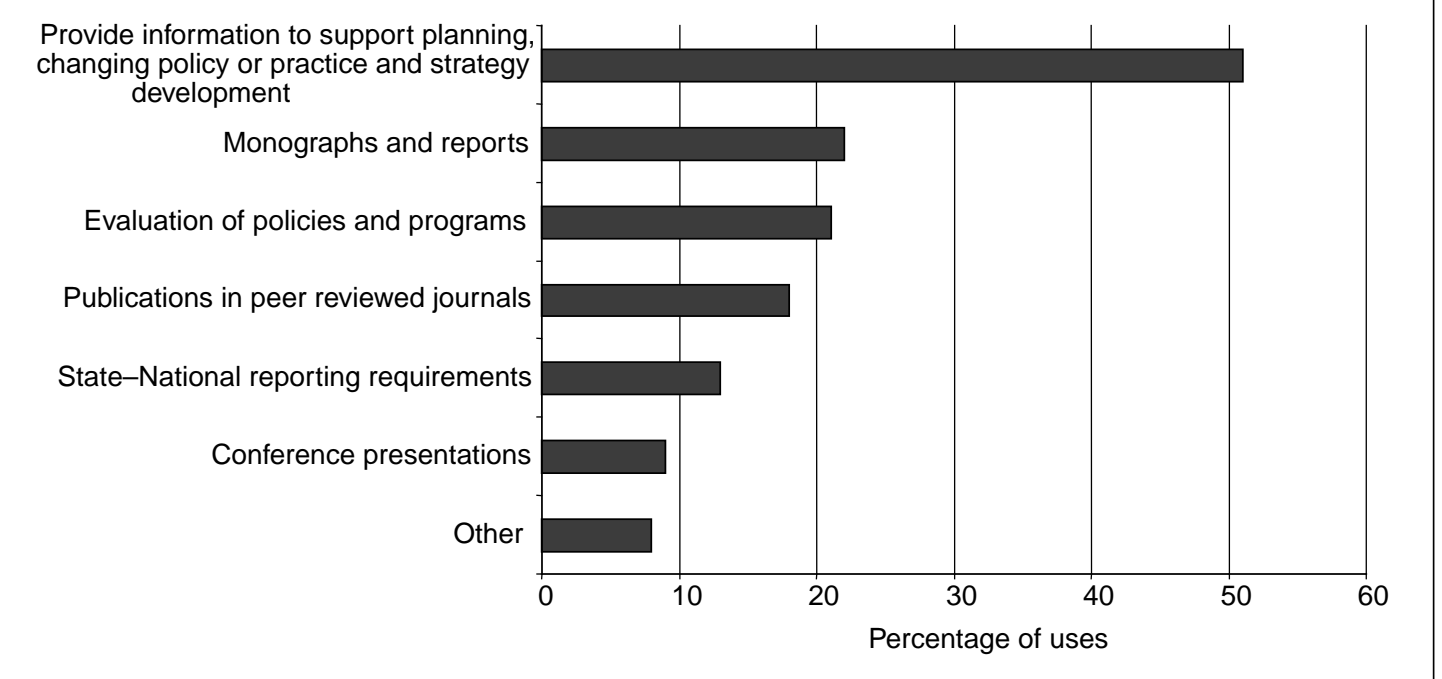




\section{TABLE 1}

\section{ACCESS TO NSW HEALTH SURVEY PROGRAM DATA [ $N=116]$}

\begin{tabular}{|llrr|}
\hline Type of data & Accessed Information & Number & (Percentage) \\
\hline Unit record data & HOIST & 14 & $(40 \%)$ \\
& Request for unit record data & 2 & $(6 \%)$ \\
& Other & 0 & $(0 \%)$ \\
\hline Summary Information & Printed Chief Health Officers Report & 18 & $(51 \%)$ \\
& Printed Older Peoples Report & 9 & $(26 \%)$ \\
& Internet Reports & 14 & $(40 \%)$ \\
& Intranet Reports & 14 & $(40 \%)$ \\
& Request for Summary tables & 0 & $(0 \%)$ \\
& Other & 4 & $(11 \%)$ \\
\hline
\end{tabular}

\section{TABLE 2}

\section{SUGGESTIONS FOR IMPROVEMENTS TOTHE NSW HEALTH SURVEY PROGRAM}

\begin{tabular}{|ll|}
\hline Area & Comments and Suggestions \\
\hline Sampling & larger rural sample \\
\hline Questionnaire Development & review of instrument by experts \\
& standardisation of questions with other data sources \\
& having consistent questions between years \\
\hline Analysis & more cleaning of survey dataset on HOIST * \\
& access to a program to convert character data to numeric data \\
\hline Reporting & separate reports for each year \\
& specific topic area reports, which may also incorporate other data sources \\
& breakdown by local government area \\
& provision of actual counts, sample number and response rate \\
\hline Marketing & more interpretation of results \\
& more information on how to access survey results \\
& more information on how to access HOIST * and better understanding of \\
\hline * The NSW Department of Health's & Health Outcomes Information Statistical Toolkit (HOIST). \\
\hline \multirow{2}{*}{. } &
\end{tabular}

\section{FIGURE 2}

\section{TOPIC AREAS OF USE OFTHE NSW HEALTH SURVEY PROGRAM INFORMATION}

Health behaviours

Breast and cervical cancer screening

Asthma

Access to and satisfaction with health services Vaccination status

Sun protection or shade policy Attitudes to smoking and public places High blood pressure, cholesterol and heart condition

Other Smoking rates Physical activity

Persistent pain

Oral health Alcohol

Screening for colorectal cancer

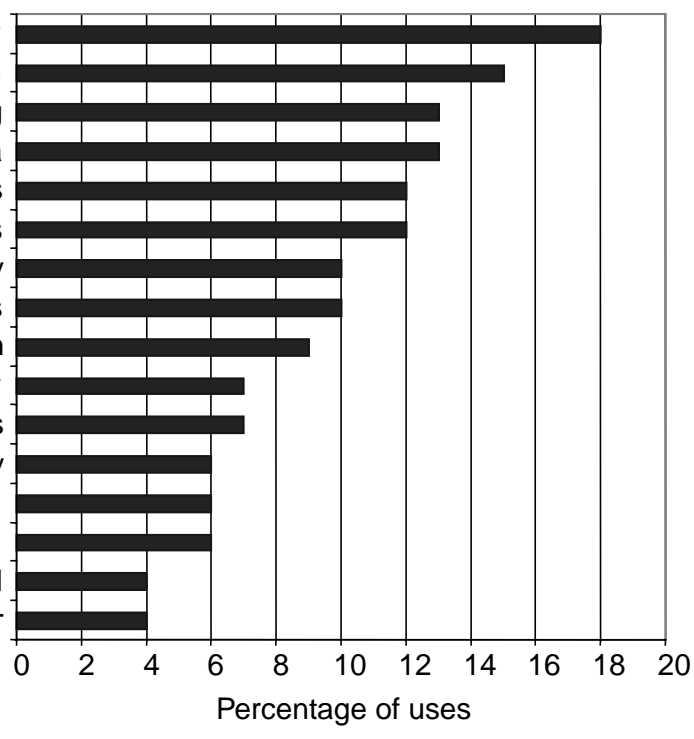




\section{Access to the data}

Data is available as summary information (that is, as aggregated data such as that presented in the Electronic Reports of the NSW Health Surveys, the Health of the People of NSW-Report of the Chief Health Officer 2000, ${ }^{2}$ or the NSW Older People's Health Survey 1999). ${ }^{3}$ or as individual unit record data, such as that found in datasets in the NSW Department of Health's Health Outcomes Information Statistical Toolkit (HOIST). Most respondents to the questionnaire (87 per cent) had accessed summary information, while less than half (43 per cent) had accessed unit record data either from HOIST or from special requests for data from the HSP.

Eighteen of the questionnaire respondents (51 per cent) had accessed summary information in the hard copy of The Health of the People of NSW-Report of the Chief Health Officer $2000,{ }^{2}$ while nine (26 per cent) had used the hard copy report NSW Older People's Health Survey 1999. ${ }^{3}$ Just under half of respondents reported that they had accessed summary information electronically via the NSW Department of Health's Intranet (14, or 40 per cent), and a similar number reported accessing it via the Internet (14, or 40 per cent) (Table1).

Of those accessing unit record data, almost all (14) reported that they obtained the data via the NSW Department of Health's Health Outcomes Information Statistical Toolkit (HOIST) facility, while only two respondents had obtained it via a special request to the Epidemiology and Surveillance Branch.

\section{USES OF NSW HEALTH SURVEY PROGRAM DATA AND INFORMATION}

The survey identified 116 separate examples of uses of the information from the HSP, covering a wide variety of purposes (Figure 1) and a wide range of topic areas (Figure 2).
HSP data has been used to fulfil State and Commonwealth reporting requirements, including reports to the Commonwealth on National Aboriginal Health Indicators, ${ }^{4}$ influenza immunisation rates for Immunise Australia, ${ }^{5}$ and indicators of satisfaction with health services for the Commonwealth Productivity Commission; ${ }^{6}$ and reports to the NSW Council on the Cost of Government, ${ }^{7}$ NSW Budget Estimates Committee, ${ }^{8}$ and NSW Treasury. ${ }^{8}$ The data have also been used to produce NSW Area Health Service Health Status Profiles, ${ }^{9}$ which support performance management within NSW Health.

HSP data have contributed to a range of monographs and reports, including:

- The Health of the People of NSW-Report of the Chief Health Officer 2000, ${ }^{2}$

- 1997 NSW Health Survey, ${ }^{10}$

- NSW Health Surveys 1997 and 1998,11

- NSW Older People's Health Survey 1999, ${ }^{3}$

- Cancer in the Bush, ${ }^{12}$

- Down River-Needs assessment of Lower Clarence, ${ }^{13}$

- NSW Older People's Health Survey, 1999Comparison between results for Mid-Western Area Health Service and NSW, ${ }^{14}$

- Healthy Northern Rivers 2002-Northern Rivers Area Health Profile, ${ }^{15}$

- reports for cancer and respiratory diseases. ${ }^{16,17}$

The HSP has provided information to support planning, policy and strategy development, including strategies for public health in NSW (such as Healthy People 2005), ${ }^{18}$ alcohol harm, ${ }^{19}$ and men's health; ${ }^{20}$ and campaigns for pneumococcal immunisation, ${ }^{21}$ influenza immunisation, physical activity (Active Australia), ${ }^{22}$ sun safety, ${ }^{23}$ and injury prevention. ${ }^{24}$

\section{FIGURE 3}

USES OF HEALTH SURVEY PROGRAM DATA BYTYPE OF USER

NSW Department of Health

Research institutions

Postgraduate education

Area Health Services

Other Government Departments

Consultants

Specialist health Services

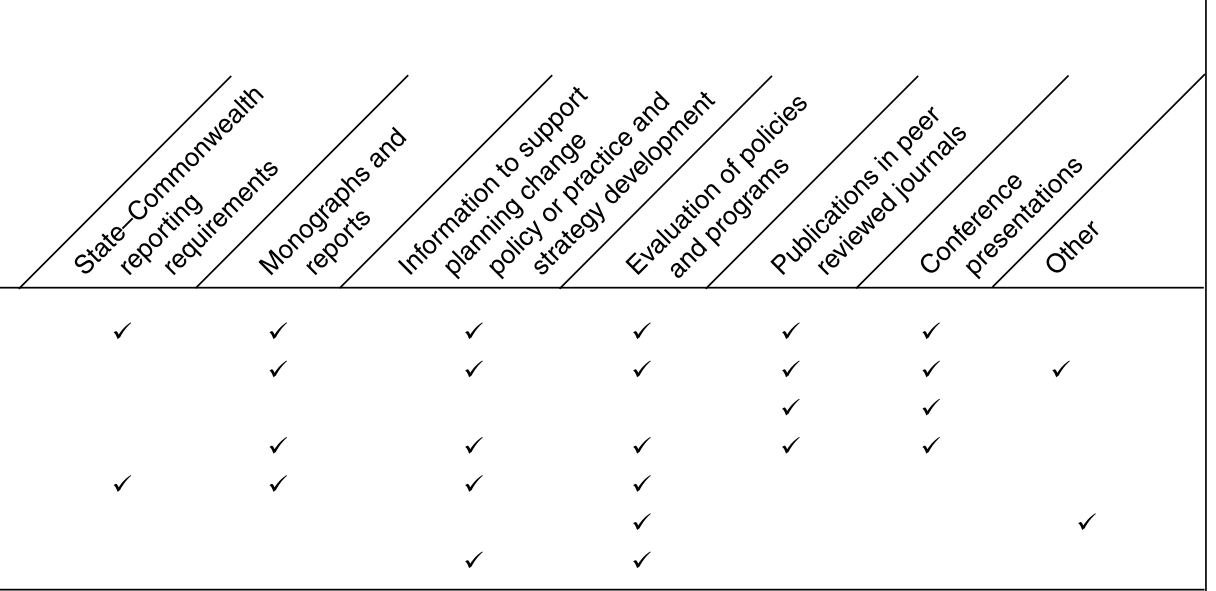

$\checkmark \quad$ NSW Health Survey used for this purpose 


\section{FIGURE 4}

\section{USES OF HEALTH SURVEY PROGRAM DATA BYTOPIC AREA}

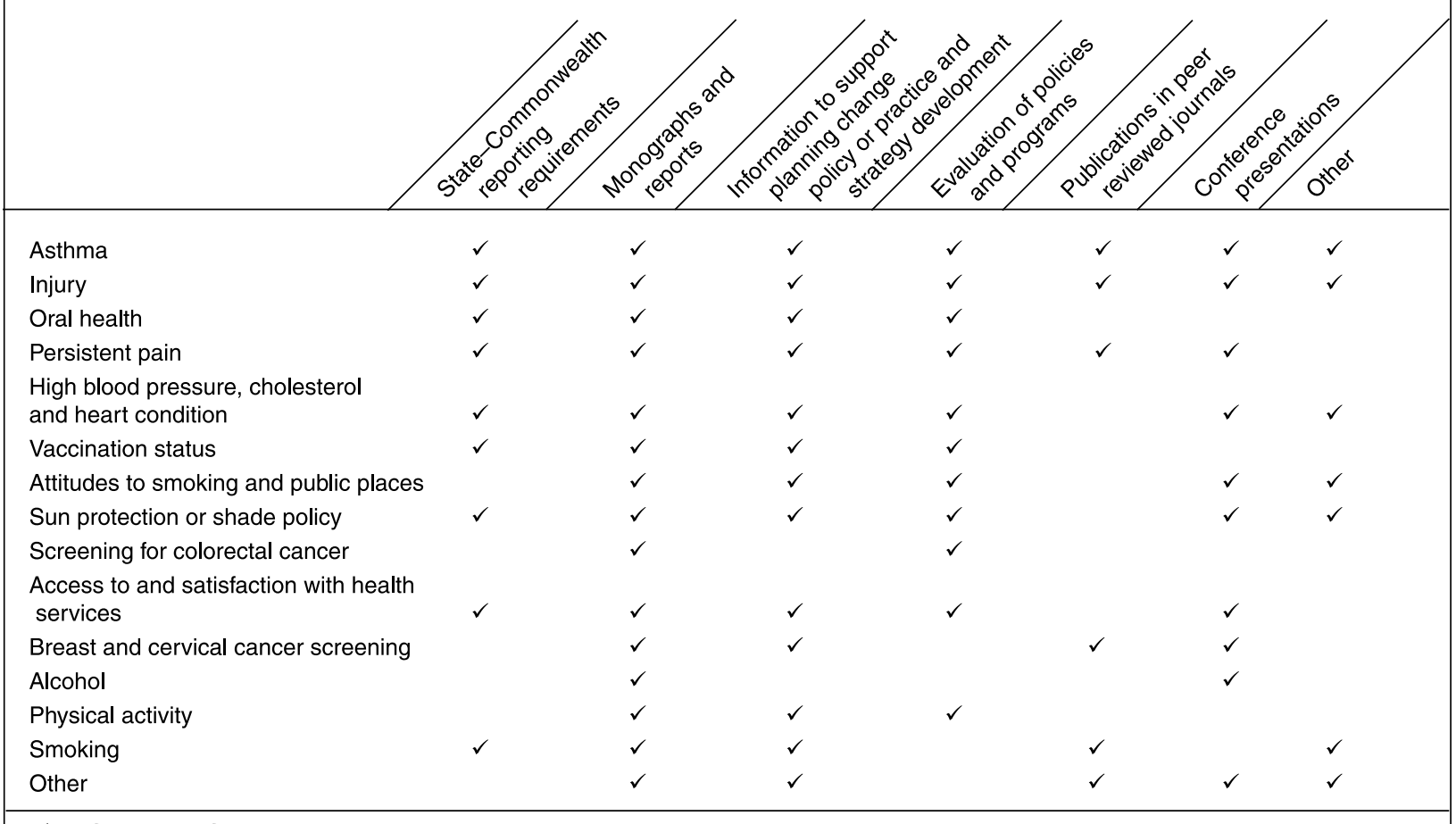

$\checkmark \quad$ NSW Health Survey used for this purpose

Uses of the HSP to evaluate policies and programs include evaluation of use of asthma 'preventer' medications, ${ }^{25}$ trends in physical activity, ${ }^{26}$ influenza immunisation campaigns, and cervical cancer screening. ${ }^{27,28}$

HSP data have been used to produce a range of publications in peer-reviewed journals, including papers on chronic pain, ${ }^{29}$ use of self-report to monitor overweight and obesity, ${ }^{30}$ cervical screening, ${ }^{28}$ use of asthma 'preventer' medications and written management plans, ${ }^{25}$ health inequalities, ${ }^{31}$ risk factors that can be modified to prevent cancer, ${ }^{32}$ informal caring, ${ }^{33}$ factors associated with smoke-free homes, ${ }^{34}$ and urinary symptoms and incontinence. ${ }^{35}$

The data have contributed to conference presentations on topics including prevalence and management of diabetes, ${ }^{36}$ prevalence of chronic pain and its interference with daily activities, ${ }^{37}$ measuring quality of life using the EQ-5D instrument, ${ }^{38}$ and alcohol harm. ${ }^{19}$

Uses of HSP by type of user and by topic area are summarised in the matrixes presented as Figures 3 and 4.

\section{Use of Area Health Service level information and other supporting sources of information}

Of the projects identified through the questionnaire, 33 (62 per cent) had involved analysis of the data at area health service level.
One-third of projects (18, or 33 pr cent) used HSP data only, while eight (15 per cent) also used the ABS National Health Survey, and 12 (22 per cent) used other additional sources of data such as National Injury Surveillance Unit reports, the National Drug Strategy Household Survey, the NSW Midwives Data Collection, the NSW Central Cancer Registry, and local health surveys.

\section{Suggestions for improvement}

Twenty-eight (80 per cent) respondents to the survey questionnaire provided suggestions for improvements to the HSP. These fell into five broad categories: sampling, questionnaire development, analysis, reporting, and marketing (Table 2).

\section{DISCUSSION}

State health departments around Australia, and overseas, are conducting regular population telephone surveys to address their requirements for population health information. Examples include:

- United States Behavioural Risk Factor Surveillance System (BRFSS), ${ }^{39}$

- California CATI (Computer Assisted Telephone Interview), ${ }^{40}$

- Hawaii Health Survey, ${ }^{41}$

- South Australian Social, Environmental and Risk Context Information System (SERCIS), ${ }^{42,43}$ 
- Western Australian Health Survey, ${ }^{44}$

- Queensland Regional Health Survey, ${ }^{45,46}$

- Victorian Health Survey program, ${ }^{47}$

- Tasmanian Healthy Communities Survey. ${ }^{48}$

Surprisingly, however, publications describing the uses made of such health survey data are scarce, except for reports from the BRFSS. ${ }^{49,50,51,52,53}$

Our survey identified a wide range of uses of NSW Health Survey Program data. Encouragingly, the most frequently reported use was to provide information to support planning and strategy development, and to change policy or practice. Remmington et al. and Figgs et al. examined uses of the BRFSS by identifying publications using BRFSS data in each of the contributing states, and through questionnaires completed by the state BRFSS managers. ${ }^{50,51}$ The main uses they identified-support for state and local health policy and planning of interventions-were similar to those found in our survey.

Barriers to use of health survey data identified in our study were similar to those found by others. Spencer et al. reported that collaboration between data creators and users was important for addressing information needs for health policy, and for prioritising these needs. ${ }^{52}$ Bloom et al. undertook focus groups with BRFSS users, and identified barriers including lack of knowledge regarding availability of the survey data and the need for larger sample sizes to examine smaller areas. ${ }^{53}$

With a move to reorient the NSW HSP to a continuous data collection from the beginning of 2002 (see the article on page 235 of this edition of the Bulletin), the information collected through the user survey, and through ongoing user feedback, will be used to refine topic and question content. It will also assist in developing mechanisms to improve the program, and to maximise the use made of its products. Figgs et al. reported an increase in the use of BRFSS data from the 1980s to the 1990s.$^{51}$ It is anticipated that the uses made of NSW HSP data will increase in a similar way as the program evolves and matures.

When planning the survey of users, we thought that many of the uses of data from the NSW HSP would be known to us. However, this was not the case, with around half of the projects we identified as being new to us. The survey was thus an important step in measuring and documenting the value of the Program. The projects that were identified have been included on a register. Any other users of the NSW HSP are encouraged to send us information about their projects so that they can be added.

\section{REFERENCES}

1. Williamson M, Baker D and Jorm L. The NSW Health Survey Program: Overview and methods, 1996-2000. Sydney: NSW Department of Health, 2001.
2. Public Health Division, The Health of the People of New South Wales-Report of the Chief Health Officer, 2000. Sydney: NSW Department of Health, 2000.

3. Public Health Division. New South Wales Older People's Health Survey 1999. Sydney: NSW Department of Health, 2000.

4. National Health Information Management Group. National summary of the 1998 jurisdictional reports against the Aboriginal and Torres Strait Islander health performance indicators. Canberra: Australian Institute of Health and Welfare, 2000.

5. Commonwealth Department of Health and Aged Care. Immunise Australia Program. National Influenza Vaccine Program For Older Australians 2000, 2001. www.health.gov.au/pubhlth/immunise/flu.htm.

6. Commonwealth Productivity Commission. Report on Government Services 2001-indicators of satisfaction with health services. www.pc.gov.au/gsp/2001/index.html.

7. Council on the Cost of Government. Health Chapter. Service Efforts and Accomplishments Report. Canberra: Council on the Cost of Government, 2000.

8. NSW Department of Health. NSW Tobacco Action Plan 20012004. Sydney: NSW Department of Health, 2001.

9. Public health Division. Area Health Service Health Status Profiles. 1999-2000 to 2000-2001 NSW Performance Agreements. Sydney: NSW Department of Health; www.health.nsw.gov.au/public-health/ahsprof/ahsprof.html.

10. Public Health Division, NSW Department of Health. 1997 NSW Health Survey-Electronic report; www.health.nsw.gov.au/public-health/hs97/index.html.

11. Public Health Division, NSW Department of Health. 1997 and 1998 NSW Health Surveys-Electronic report. www.health.nsw.gov.au/public-health/nswhs/index.html.

12. Jong K, Smith DP, Yu XQ, O'Connell D, Armstrong BK. Cancer in the Bush: Remoteness and cancer incidence, mortality and survival in New South Wales. Sydney: NSW Cancer Council and Southern Cross Institute for Health Research, August 2001 (in press).

13. FPA Health 'Down River'-A needs assessment of the Lower Clarence. Sydney: FPA Health, 2001.

14. Robson G. NSW Older People's Health Survey, 1999Comparison between results for Mid-Western Area Health Service and NSW. Orange: Public Health Unit, Mid-Western Area Health Service, 2000.

15. Southern Cross Institute of Health Research. Healthy Northern Rivers 2002: Northern Rivers Area Health Profile. Lismore: Northern Rivers Area Health Service, 1998; www.nrihr1web/ HNR2002/default/htm.

16. Centre for Research and Clinical Policy. Background Working Paper 2: Current Situational Analysis-Cancer. Sydney: NSW Department of Health, 2000.

17. Centre for Research and Clinical Policy. Background Working Paper 4: Current Situational Analysis-Respiratory Diseases. Sydney: NSW Department of Health.

18. Public Health Division. Healthy People 2005. Sydney: NSW Department of Health, 2000.

19. Population Health Unit. Indicators of alcohol associated harm in western NSW, 2000. Broken Hill: Far West Area Health Service, 2001.

20. Men's Health Information and Resource Centre. Profile of Men's Health in the Greater Murray Area Health Service. Richmond, NSW: University of Western Sydney, June 2001. 
21. Australian Department of Health and Aged Care, National Indigenous Pnuemococcal and Influenza Immunisation Program; www.health.gov.au/pubhlth/immunise/ indigenous.htm.

22. Health Promotions Branch, NSW Department of Health. Active Australia programs; www.health.nsw.gov.au/publichealth/health-promotion/improve/physicalactivity/pa_new/ active_aust/aa_index.htm.

23. Health Promotions Branch, NSW Department of Health. Sun safety campaigns; www.health.nsw.gov.au/public-health/ health-promotion/improve/sun/sunindex.html.

24. Health Promotions Branch, NSW Department of Health. Injury prevention campaigns; www.health.nsw.gov.au/publichealth/health-promotion/improve/injury/injindex.htm.

25. Marks GB, Jalaludin BB, Williamson M, Atkin NL, Bauman A. Use of 'preventer' medications and written asthma management plans among adults with asthma in New South Wales. NSW Department of Health Asthma Data Working Group. Med J Aust 2000; 173(8): 407-410.

26. Power J. Audit of Physical Activity Opportunities for People Over 50 in South Western Sydney. Liverpool, NSW: Health Promotion Unit, South Western Sydney Area Health Service (forthcoming publication).

27. NSW Cervical Screening Program-NSW Pap Test Register. Cervical Cancer Screening in New South Wales: Annual Statistical Report 1999. Sydney, NSW Cancer Council, 2001.

28. Mamoon H, Taylor R, Morrell S, Wain G, Moore H. Cervical screening: population-based comparisons between selfreported and registry-based Pap test rates. Aust N Z J Public Health (in press).

29. Blyth FM, March LM, Brnabic AJ, Jorm LR, Williamson M, Cousins MJ. Chronic pain in Australia: a prevalence study. Pain. 2001; 89(2-3): 127-134.

30. Flood V, Webb K, Lazarus R, Pang G. Use of self-report to monitor overweight and obesity in populations: some issues for consideration Aust NZ J Public Health 2000. 24(1); 96-9.

31. Moore H, Jorm LR Measuring health inequalities in New South Wales. NSW Public Health Bulletin 2001: 12: 120-125.

32. Moore H, Jorm LR, Vita P. Measuring risk factors that can be modified to prevent cancer. NSW Public Health Bulletin 2001 12: 2-6.

33. Muscatello D, Sainsbury P, Rissel C. Informal caring in Central Sydney. NSW Public Health Bulletin 2001; 12: 12-13.

34. Rissel C, Merom D. Factors associated with smoke-free homes in NSW: Results from the 1998 NSW Health Survey. Tobacco Control (in press).

35. Muscatello DJ, Rissel C, Szonyi G. Urinary symptoms and incontinence in an urban community: prevalence and associated factors in older men and women. Internal Medicine Journal 2001; 31: 151-160.

36. NSW Health Survey Program. The prevalence and treatment of people with diabetes in NSW, Australia-Are we measuring up to clinical guidelines. International Conference on Global Issues and Perspectives in Monitoring Behaviours in Populations: Surveillance of Risk Factors in Health and Illness, Atlanta, 1999.

37. Centre for Pain Management and Research, Royal North Shore Hospital. Prevalence of Chronic Pain and Interference with
Daily Activities. Australasian Epidemiological Association Meeting, Canberra, November 2000.

38. Owen T, Jorm L and Williamson M. EuroQol-5D: Measuring health related quality of life using computer-assisted telephone interviewing in NSW. 32nd Public Health Association of Australia Annual Conference, Canberra, November 2000.

39. Center for Disease Control and Prevention. Behavioral Risk Factor Surveillance System User's Guide. Atlanta: US Department of Health and Human Services, Centre for Disease Control and Prevention, 1998.

40. California Computer Assisted Telephone Interviews (CATI); www.ccrcal.org/catibro.htm.

41. Hawaiian Department of Health. The Hawaii Health Survey; www.state.hi.us/doh/stats/surveys/hhs.html.

42. Centre for Population Studies in Epidemiology. Social, Environmental and Risk Context Information System (SERCIS). Adelaide: South Australian Department of Human Services; www.dhs.sa.gov.au/pehs/cpse/SERCIS.html.

43. Wilson D, Wakefield MA, Taylor A. The South Australian Health Omnibus Survey. Health Promotion Journal of Australia 1992; 2: 47-49.

44. Daly A, Milligan R, Unwin E, Thomson N. The 1995 Western Australian Health Survey: Overview. Perth: Health Authorities of Western Australia, February 1996; www.health.wa.gov.au/ publications/annual_report/63_4.html.

45. Watson EK, Firman DW, Heywood A, Hauquitz AC, Ring I. Conducting regional health surveys using a computer-assisted telephone interviewing method. Aust J Public Health October 1995; 19(5): 508-11.

46. Watson EK, Firman DW, Baade PD, Ring I. Telephone administration of the SF-36 health survey: validation studies and population norms for adults in Queensland. Aust N Z J Public Health August 1996; 20(4): 359-63.

47. Public Health Division, Department of Human Services. Victorian Population Health Surveys; www.dhs.vic.gov.au/ phd/hce/epid/vphs.htm.

48. Health and Wellbeing in Tasmania: Results of the Healthy Communities Survey 1998; www.dhhs.tas.gov.au/services/ healthy_living/pages/public.html.

49. Center for Disease Control, National Center for Chronic Disease Prevention and Health Promotion. BRFSS in Action-A state by state listing of how data are used; www.cdc.gov/nccdphp/brfss/dataused.htm.

50. Remington PL, Smith MY, Williamson DF, Anda RF, Gentry EM, Hogelin GC. Design, characteristics, and usefulness of state-based behavioral risk factor surveillance: 1981-87. Public Health Rep 1988; 103: 364-378.

51. Figgs LW, Bloom Y, Dugbatey K, Stanwyck CA, Nelson DE, Brownson RC, Uses of Behavioral Risk Factor Surveillance System data, 1993-1997. Am J Public Health May 2000; 90(5): 774-6.

52. Spencer DL, Reed SJ, Atkinson D, Kalsbeek WD. Design of a survey to inform state health decision making: a collaborative effort. Am J Prev Med; 1997; 13(6 Suppl): 69-74.

53. Bloom Y, Figgs LW, Baker EA et al. Data uses, benefits and barriers of the Behavioral Risk Factor Surveillance System: a qualitative study of users. Journal Public Health Management Practice. 2000; 6, 78-86. 